\title{
El príncipe de Santo Buono, sus deudos y criados en el virreinato del Perú (1716-1720)
}

\author{
The Prince of Santo Buono, his Relatives and Servants \\ in the Viceroyalty of Peru (1716-1720)
}

\author{
María Ángeles Gálvez Ruiz \\ ORCID iD: http://orcid.org/0000-0002-7289-4176 \\ Universidad de Granada
}

Las circunstancias sobre el nombramiento del príncipe de Santo Buono como virrey del Perú y el traslado de la corte virreinal dan inicio al presente trabajo. Ha sido también objeto de estudio la composición de los séquitos y otros servidores agregados que acompañaron a Santo Buono al Perú, así como el papel que cumplieron varios de sus deudos y criados en el gobierno virreinal. Sus acciones influyeron de manera destacada en el juicio de residencia del virrey.

Palabras clave: Santo Buono; Perú; Corte Virreinal; Deudos; Criados; Juicio de Residencia.

The circumstances surrounding the appointment of the Prince of Santo Buono as Viceroy of Peru and the transfer of the viceregal court are the basis of this investigation. The composition of the entourages and other aggregate servants who accompanied Santo Buono to Peru, as well as the role played by several of his relatives and servants in the viceregal government, have also been studied. His actions had an outstanding influence on the the viceroy's trial of residence.

KeYwords: Santo Buono; Peru; Viceregal Court; Relatives; Servants; Juicio de Residencia.

Copyright: (C) 2020 CSIC. Este es un artículo de acceso abierto distribuido bajo los términos de la licencia de uso y distribución Creative Commons Reconocimiento 4.0 Internacional (CC BY 4.0). 


\section{Introducción}

Cármine Nicolás Carácciolo, nacido en Bucchianico el 5 de julio de 1671, fue el quinto príncipe de Santo Buono y octavo duque del Castell di Sangro. ${ }^{1}$ Aparte del disfrute de otros títulos, este noble napolitano fue nombrado por Felipe $\mathrm{V}$ embajador extraordinario ante el pontificado de Clemente XI en 1702, poco después sería premiado con la Grandeza de España ${ }^{2}$ y, en 1703, designado embajador ordinario en Venecia. ${ }^{3}$ Dado que su lealtad al monarca español le acarreó la privación de sus propiedades napolitanas, ocupadas por los ejércitos austriacos, ${ }^{4}$ fue nombrado posteriormente virrey y gobernador del Perú a fin de recompensarlo de tales pérdidas. ${ }^{5}$ De las expropiaciones a los Grandes españoles afines a la casa de Habsburgo, Felipe V repartió importantes sumas compensatorias a los nobles y fieles napolitanos. Santo Buono recibiría una anualidad de 105.000 pesos, ${ }^{6}$ aunque no por ello mostró renuncia o conformidad a la gran pérdida que sufrió en 1707 en el reino de Nápoles. ${ }^{7}$

Desde el año 1711, según notas de Vargas Ugarte, residía en la corte de España junto a su esposa Constanza Ruffo, hija del duque de la Bragnara, quien parece que ejerció un papel decisivo en la promoción y nombramiento

1 Patrucco, 2005, 113-125. El autor aporta numerosos datos biográficos y relativos a su formación humanista, parte de estos tomados de Salazar, 1894. Destacamos, en la vertiente intelectual del príncipe, el papel asignado por el virrey Medinacelli para la creación de la Accademia nel Real Palagio y su producción literaria. Además del capítulo de la tesis del autor destinado al estudio de los miembros del séquito del virrey, véase también Patrucco, 2017, 225-249.

2 Real despacho a favor de don Nicolás Carracciolo, concediéndole la grandeza de España de primera clase, unida al título de Príncipe de Santo Buono, que posee, año de 1712, Archivo Histórico Nacional, Madrid (AHNM), Consejos, 8976, A.1712, exp. 227.

3 Mendiburu, 1931, III, 293.

4 Rizo-Patrón Boylan, 2001, 4. Declarado en contumacia por la nueva administración imperial, se decretó secuestro de sus bienes. Salazar, 1894, 127-129, en Patrucco, 2005, 115.

5 Los títulos de virrey y gobernador del Perú, presidente de la audiencia de la ciudad de los Reyes y capitán general de la provincia del Perú aparecen fechados el 20 de diciembre de 1711 en los libros de la Contaduría Principal de la Casa de la Contratación, Archivo General de Indias, Sevilla (AGI), Contratación, 5468, n. 2, r. 12, f. 11r-16r. De forma errónea, algunos autores han ubicado su nombramiento como virrey entre los años 1713 y 1715, pero los títulos insertos en la documentación mencionada nos confirman la data del año 1711. Hay otras evidencias documentales como el señalamiento de su salario para el solio virreinal el 4 de agosto de 1712. AGI, Lima, 1067, indicado en Moreno Cebrián y Sala i Vila, 2004, 157; o la existencia de dos documentos del año 1712 relacionados con Santo Buono y su futuro cargo en el virreinato peruano, como veremos en este trabajo.

6 Patrucco, 2005, 116

7 Antes de su viaje a la Indias redacta en Cádiz una memoria, fechada el 23 de abril de 1713, bajo el título «Memoria de los estados, rentas y otros bienes, que posee la Casa del Príncipe de Santo Buono en el Reyno de Nápoles en el año de 1707, quando los alemanes ocuparon dicho Reyno». Idem. 
de Santo Buono para el virreinato del Perú. Hay evidencias de que doña Constanza pertenecía al círculo inmediato del rey y de que estaba igualmente próxima al futuro cardenal italiano Giulio Alberoni, quien influyó sobre ella y sobre otros personajes para alentar el segundo matrimonio de Felipe V con Isabel de Farnesio. ${ }^{8}$

Partió de Cádiz rumbo al Perú el 14 de noviembre de 1715 a bordo del navío Santa Rosa, ${ }^{9}$ bajo el mando de Nicolás de la Rosa, conde de Vega Florida. Se conocen detalles de la travesía gracias al diario de un viajero que, señala Fernández Duro, formó parte del séquito virreinal. ${ }^{10} \mathrm{La}$ entrada de Santo Buono en Lima tuvo lugar el 5 de octubre de 1716, ${ }^{11}$ relevando al entonces virrey interino fray Diego Morcillo Rubio de Auñón, arzobispo de Charcas, a quien el príncipe entregaría de nuevo el gobierno del Perú cuando renunció al cargo el 26 de enero de 1720.

En el presente estudio se analizan las circunstancias que rodearon el nombramiento del príncipe italiano para el solio virreinal, donde cabe mencionar una serie de denuncias previas llegadas a la corte acerca de las redes clientelares y las políticas de favoritismos ejercidas por virreyes anteriores en el Perú. Pese a las críticas y repulsas expresadas por tales prácticas desde diversos círculos, damos cuenta de un pacto secreto establecido entre el nuevo mandatario y el rey, sobre el cual se sentaban las bases del nuevo gobierno de Santo Buono. Además de fungir una política de compensaciones en una doble dirección, señalamos las licencias otorgadas para ir al Perú a una extensa cohorte de familiares y criados, donde destacaría un grupo notable de italianos. El tema ha sido clave tanto para conocer la composición de los dos séquitos que acompañaron al virrey, como para determinar algunas funciones notorias de personajes principales. Tanto sus acciones como el trato de favor recibido de la mano del príncipe se convirtieron en

8 Rizo-Patrón Boylan, 2001, 5.

9 AGI, Contratación, 5468, n. 2, r. 12, f. 5r.

10 El viaje se encuentra documentado en Salazar, 1894, 138. Una anotación de Vargas Ugarte indica que «según el librero Maggs, Cat. 502, n. ${ }^{\circ}$ 5.268, existe traducción castellana de este viaje», Vargas Ugarte, IV, 1981, 110. La flota en la que viajó el príncipe, su familia y demás empleados la componían el navío Santa Rosa, dos naves mercantes, llamadas San Carlos y Ninfa, y un patache bajo el nombre El Cubano. Partieron junto a él los obispos de Santa Marta, Panamá, Arequipa y Buenos Aires, además de una misión de once frailes capuchinos destinados a Maracaibo, además del pasaje ordinario en el que figuraban los mercaderes y militares. La llegada a Cartagena tuvo lugar el 9 de enero de 1716. Varios meses después, Santo Buono hizo su entrada en Lima como virrey. Fernández Duro, 1895-1903, VI, 122-123.

11 Su recibimiento con el boato clásico de la época quedó plasmado en la obra poética de Bermúdez de la Torre y Solier, 1717. 
un arma arrojadiza por los sectores contrarios a Santo Buono y a los suyos instalados en Lima; además, fueron la fuente principal para formular una serie de acusaciones contra el virrey en el transcurso del juicio de residencia que se le abrió al término de su mandato.

Entre los diversos estudios que tratan el patronazgo cultivado por los virreyes, mencionamos la obra de Rosenmüller sobre la corte del duque de Alburquerque en el virreinato de la Nueva España a principios del siglo XVIII. ${ }^{12}$ La perspectiva comparada de este virrey con Santo Buono no solo es pertinente dada su proximidad temporal como vicesoberanos, sino porque ambos gobiernos se encuadran en los nuevos aires políticos que trajo el reinado de Felipe V, donde se intentó restringir o, al menos, controlar los nombramientos de cargos en deudos y criados de los virreyes. Pese a ello, el ejercicio del poder de ambos virreyes no se puede comprender sin tener en cuenta la existencia, en cada caso, de una red clientelar tejida de forma compleja y en cuya trama principal se encontraban esos deudos y criados. Los clientelismos y las intrigas palaciegas eran igualmente la nota dominante en las dos cortes virreinales.

Para el caso peruano, el fenómeno clientelar en torno a las figuras de los máximos mandatarios estaba consolidado desde la primera mitad del siglo XVII. Así lo muestra Torres Arancivia en su estudio sobre la actuación de dos virreyes destacados del período, el príncipe de Esquilache y el conde de Chinchón. ${ }^{13}$ Entre las principales vías de promoción a favor de familiares y criados de sendos gobernantes estaba la distribución de oficios, rentas y mercedes, además de apoyar los enlaces matrimoniales de sus deudos con la elite criolla. El autor analiza la reacción y crítica que causó esta política de favoritismos entre los grupos de poder criollos, a la que enfrentaron sus derechos como «beneméritos» con base a lo estipulado legalmente por la corona. ${ }^{14}$ No obstante, la política matrimonial aludida, que venía a emparentar criados, parientes y allegados de un virrey con la elite criolla, pudo generar situaciones paradójicas como fue el caso del virrey de Montesclaros, cuyo perfil procriollo sirvió igualmente para proveer de oficios a estos sectores de la elite social. ${ }^{15}$

12 Rosenmüller, 2008.

13 Torres Arancivia, 2006, 109-164.

14 Ibidem, 165-194.

15 Con esta óptica, se ofrece una visión particular del nepotismo virreinal en la figura del marqués de Montesclaros en Perú para el siglo XVII por Latasa, 2012, 49-84. 


\section{Los anónimos y pactos secretos en torno a su nombramiento}

El nombramiento de Santo Buono tuvo lugar tras el fallecimiento de Manuel de Oms y Santa Pau, primer marqués de Castelldosrius. Pero antes del arribo del príncipe al Perú, se sucedieron una serie de interinatos en el solio virreinal, destacando primero Diego Ladrón de Guevara, obispo de Quito, y después, Diego Morcillo, arzobispo de Charcas. ${ }^{16}$

Como antecedentes inmediatos al advenimiento de Santo Buono al solio virreinal, mencionamos las noticias que llegaban a la corte sobre la corrupción de los gobernantes y las prácticas fraudulentas de virreyes, como las del marqués de Castelldosrius, ${ }^{17}$ que provocaron cierta alarma y voces de acusación en España. Este virrey acumuló diversas denuncias en su contra hasta ser destituido temporalmente en 1709, aunque lograra recuperar el cargo con una hábil maniobra de pago y contribución a la Corona. La operación venal consistió en el beneficio de indulto ante los posibles cargos que se le pudiesen imputar, además de un intento de prórroga en el gobierno del Perú. ${ }^{18}$

Existe un documento anónimo del año 1712 que describía los males públicos del Perú relacionados con los intereses y beneficios personales de virreyes, jueces y gobernadores que, una vez llegado a manos del presidente del Consejo de Indias, el conde de Frigiliana, este quiso que se estimara para hacer saber las recomendaciones de buen gobierno a Santo Buono como futuro virrey. Entre las denuncias se citaban una serie de perjuicios ocasionados en el mandato del marqués de Castelldosrius, señalando su responsabilidad en la muerte de más de quinientos tributarios y los enormes gastos que ocasionó su viaje por tierra desde Paita a Lima. ${ }^{19}$ Igualmente, el reservado testimonio señalaba la avaricia de virreyes, jueces y gobernadores movidos solo por sus propios intereses, así como «el maleficio de

16 La sucesión en el solio virreinal tras la muerte del marqués de Castelldosrius en abril de 1710 fue la siguiente: «La Audiencia, presidida por Miguel Núñez de Sanabria lo asume, al fallecer el Marqués de Castell dos Rius, (25 de abril de 1710) y lo entrega a D. Diego Ladrón de Guevara el 14 de septiembre del mismo año. Éste, a su vez, lo devuelve a la Audiencia, presidida por entonces por D. Mateo de la Mata Ponce de León el 2 de marzo de 1716 y ésta hace dejación del gobierno en manos del Arzobispo D. Diego Morcillo el 15 de agosto», Vargas Ugarte, 1981, IV, 95. Morcillo se mantuvo como virrey interino hasta la llegada de Santo Buono el 5 de octubre de 1716.

17 Moreno Cebrián y Sala i Vila, 2004, 17-150.

18 Un examen a través de documentos de carácter epistolar entre agentes de la corte del virrey, el mismo Castelldosrius y otras personas de la confianza del rey, se puede ver en Burgos Lejonagoitia, 2010, 317-338.

19 Moreno Cebrián y Sala i Vila, 2004, 100. 
los Virreyes» de requerir elevadas sumas de dinero para permitir el pase a aquellos que llegaban de España para ejercer de corregidores o en otros oficios. Estas u otras prácticas fraudulentas se exponían en el documento secreto de $1712 .{ }^{20}$

En tal ambiente de denuncia situamos los inicios del príncipe como futuro virrey, quien emitió un memorial, también en 1712, dirigido al secretario de despacho Grimaldo, donde igualmente criticaba el enriquecimiento personal de los virreyes y la gran corruptela que había en la administración indiana, con los consiguientes perjuicios ocasionados a la Monarquía. ${ }^{21}$ Exponía el príncipe una extensa lista de prácticas corruptas por parte de los virreyes, aunque, a su vez, parecía justificarlas al relacionar su principal causa con los insuficientes salarios que, a su juicio, percibían estos gobernantes. ${ }^{22}$

Sin embargo, señala Andújar un interés privado tras el memorial, dado que Santo Buono lograba pactar con la corona un acuerdo para, en palabras del autor, «no robar demasiado» a cambio de fijar una cantidad determinada para la corona. El acuerdo se concretó en la remisión anual desde el Perú de dos millones de pesos, a cambio de poder sacar el virrey a su arbitrio de las cajas de Lima la cantidad de hasta 600.000 pesos «para gastos del real servicio» ${ }^{23}$ Tal pacto quedó sellado por escrito el 19 de enero de $1713,{ }^{24}$ al que se añadió un acuerdo secreto consistente en partir para Indias con dos títulos de Castilla - de conde o de marqués- cuyo producto de su venta iría a parar a partes iguales al duque de Havreé y al marqués de Crevencour, como gracias del rey por los matrimonios que ambos habían contraído. ${ }^{25}$ Se esperaba de Santo Buono una operación de enajenación de los títulos a muy buen precio en las Indias y, a cambio, el italiano estrechaba lazos con Palacio dado que el duque de Havreé se había casado con Ana María de Lanti de la Rovère, sobrina de la princesa de los Ursinos. El segundo matrimonio encierra un interés mucho más personal, pues el enlace del

20 Documento adjunto a la carta del conde de Frigiliana, Madrid, 4 de octubre de 1712, AHNM, Estado, 2334. Citado en Ibidem,100-101.

21 AHNM, Estado, 2319, anotado por Andújar Castillo, 2008, 297.

22 Ibidem, 296-298.

23 Calcula Andújar que tal negociación aseguraba a Santo Buono el $10 \%$ de la recaudación obtenida durante los tres años de gobierno, y que los primeros beneficios recibidos fueron «con cargo a los indultos de los delitos atrasados por ilícito comercio, fraudes en la rendición de cuentas y extravíos de azogue de Huancavelica». Ibidem, 297-298.

24 Ibidem, 298.

25 Ibidem, 298-299. 
marqués de Crevencour se realizó con Clara Irene Caracciolo, la hija mayor de Santo Buono. ${ }^{26}$ Sin duda, se trataba de un gran partido el casamiento de su hija con el primogénito del príncipe de Maserano, habida cuenta de las poderosas relaciones que Crevencour mantenía en la corte de Madrid, perteneciendo al círculo íntimo de Isabel de Farnesio. Pero la dote prometida como donación propter nupcias, con el compromiso de pago puntual según lo estipulado en las capitulaciones firmadas en Madrid en 1712, fue una nueva carga para el futuro gobernante, que saldría a relucir, años después, en el juicio de residencia. Parece que el futuro virrey tenía muy buenas expectativas económicas con su viaje a las Indias para saldar la promesa dotal, ya que buena parte del montante de la dote quedó condicionado a entregarse una vez que hubiera tomado posesión de su cargo de virrey, lo que indica los beneficios que esperaba reunir Santo Buono a su llegada a la corte de Lima. ${ }^{27}$

En aquel pacto con la corona, y en el marco de una política generalizada de compensaciones prevista a los virreyes peruanos, se le sumaba al sueldo de 2.000 doblones de a dos escudos de oro ${ }^{28}$ la cantidad de 4.800 .000 reales de plata, por real cédula de 19 de enero de 1713, para resarcirle de la pérdida de las rentas del estado de Cusano al marcharse a Indias. ${ }^{29}$ Informa Moreno Cebrián que tal libramiento tenía la peculiaridad de que «por tribunal alguno se le pidiese cuenta de esa cantidad», indicando además que podía ser utilizado para «el cumplimiento de los particulares encargos y reservados negocios que SM le fiaba». ${ }^{30} \mathrm{Tal}$ sustancial monto, que podía utilizarse para menesteres relacionados con las finanzas reales, era señal del estrecho vínculo que mantenía el príncipe con la Corona. Además, otras

26 Ambos títulos en blanco no se vendieron finalmente en Indias, pero sí fueron enajenados en España para responder a los intereses arriba mencionados. Idem.

27 Andújar señala que en la capitulación matrimonial se ofrecía una fuerte dote de 10.000 doblones - 600.000 reales_- de los cuales 2.000 doblones se comprometían al contado el día de boda; otros 6.000 doblones se «obliga a conducirlos y remitirlos a España con la primera expedición de galeones que salieren de los puertos del Perú después de haber tomado posesión de aquel virreynato [...]». Los restantes 2.000 doblones serían satisfechos a la vuelta de su gobierno en el Perú, en el plazo de un año o cuando recuperase los estados que tenía en el Reino de Nápoles. Indica el autor que, después de la firma de esta capitulación matrimonial, se firmó una escritura de prórroga para pagar en el término de un año los 2.000 doblones que antes se había comprometido al contado, y que la deuda por el importe total de los 10.000 doblones no fue saldada hasta diez años después, en febrero de 1722, es decir, cuando ya había renunciado al cargo y abandonado el Perú. Ibidem, 300.

28 Señalamiento de salario para el príncipe de Santo Buono fechado en el Buen Retiro, 4 de agosto de 1712, AGI, Lima, 1067, citado en Moreno Cebrián y Sala i Vila, 2004,157.

29 Idem.

30 Ibidem, 158. 
compensaciones a virreyes posteriores, como la que fue otorgada al virrey Castelfuerte de 160.000 reales de plata al año en concepto de ayuda de costa,${ }^{31}$ eran infinitamente menores que el montante referido para Santo Buono. No obstante, hay que matizar que esta política de «compensaciones» hay que entenderla tanto en el contexto específico de unos sueldos desactualizados desde 1639, que hacía oficial dicha práctica, como de acuerdo a la costumbre de conceder mercedes dentro de la cultura del favor y de la gracia del soberano.

A tales privilegios debe añadirse la suntuosa corte virreinal que Santo Buono instalaba en Lima, cuyo brillo y opulencia seguía el ejemplo de cortes anteriores como la del mismo Castelldosrius. ${ }^{32}$ Este virrey había introducido nuevos comportamientos políticos y culturales en la vida cortesana de Lima, fruto de su afrancesamiento y origen catalán que, como refiere Sala i Vila, supuso un quiebre en el ejercicio del poder, donde varios sectores criollos sintieron discriminación frente a los nuevos actores de los que se hizo rodear el marqués de Castelldosrius. ${ }^{33}$

\section{El traslado del séquito a Indias}

Constan varias licencias y permisos para que Santo Buono pasara al Perú «llevando en su compañía un hijo suyo y los demás allegados y sujetos que ha recibido para su familia», ${ }^{34}$ autorizaciones que se remitían a la Casa de la Contratación donde se relacionaban inicialmente un total de sesenta y cinco pasajeros, incluidos el virrey, su esposa y dos de sus hijos, como veremos más adelante. ${ }^{35}$

En cuanto a los miembros que formaban parte de la comitiva del virrey, existen dos memorias separadas conformadas por el séquito del príncipe y el de su esposa. La composición de ambos figura a continuación:

31 Ibidem, 157.

32 Ibidem, 163

33 Para un estudio del séquito y la cultura política cortesana de Castelldosrius, véase Sala i Vila, 2004, 31-68.

34 AGI, Contratación, 5468, n. 2, r. 12, f. 2r.

35 Remitidas al presidente y oficiales de la Casa de la Contratación de Sevilla y firmadas por Bernardo Tinajero de la Escalera, secretario del Perú del Consejo de Indias, fechadas en Madrid a 11 de febrero de 1713 y 30 de julio de 1714. AGI, Contratación, 5468, n. 2, r. 12, f. 1r-10r. 


\section{Cuadro 1}

MEMORIA DE LA FAMILIA QUE HA DE LLEVAR AL PERÚ LA SEÑORA PRINCESA DE STO. BUONO ${ }^{36}$

\begin{tabular}{|c|c|c|}
\hline Nombre y apellidos & Función/familiar & Lugar de origen \\
\hline La S. ${ }^{a}$ Princesa de Santo Bueno [sic] & esposa & Venecia $^{37}$ \\
\hline La S. ${ }^{a}$ D. ${ }^{a}$ Julia Quitería Caracholo & hija & Venecia $^{38}$ \\
\hline D. ${ }^{a}$ Rosa Manchineli & criada & Nápoles \\
\hline D. ${ }^{a}$ Antonia Quiroga & criada & Madrid \\
\hline D. ${ }^{a}$ Elvira Jiménez & criada & Toledo \\
\hline D. ${ }^{\mathrm{a}}$ Clara Batil & criada & Bruselas \\
\hline D. ${ }^{a}$ Herminia de Torres & criada & Turín \\
\hline D. ${ }^{a}$ María Berti & criada & Génova \\
\hline Cathalina Bosque & lavandera & Mons (Flandes) \\
\hline D. Ygnacio Domínguez & caballerizo (camarero mayor) $^{39}$ & Tarazona \\
\hline D. Fabricio Bartoli & mayordomo (caballerizo) ${ }^{40}$ & Madrid \\
\hline D. Theodoro Candioti & criado (mayordomo) ${ }^{41}$ & Cádiz $^{42}$ \\
\hline D. ${ }^{a}$ Leonor Mexía & mujer de Theodoro Candioti & Cádiz \\
\hline 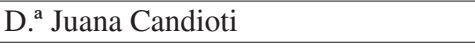 & hija de Theodoro Candioti & Cádiz \\
\hline D. ${ }^{a}$ Elvira Blanco & criada de Theodoro Candioti & Cádiz \\
\hline D. Francisco Candioti & paje & Cádiz \\
\hline D. Rodrigo Candiote & paje & Cádiz \\
\hline D. Pedro Candiote & paje & Cádiz \\
\hline D. Antonio Pañés & paje & Madrid \\
\hline D. Pablo Bruneti & capellán & Nápoles \\
\hline D. Roque Zerrutti & maestre de capilla & Bolonia \\
\hline D. Francisco Gómez & ayuda de cámara & Gante \\
\hline Baptista Querin & botiller & París \\
\hline Antonio Baren & cocinero & París \\
\hline Joseph Vitorio & lacayo & Nápoles \\
\hline
\end{tabular}

Fuente: Elaboración propia a partir de la documentación referenciada.

36 Información de una copia de la memoria original remitida desde la Secretaría del Perú del Consejo de Indias a la Casa de la Contratación, Madrid, 30 de julio de 1714, AGI, Contratación, 5468, n. 2 , r. 12 , f. 7 r-7v. Se respeta la grafía original de los nombres y apellidos.

37 Rizo-Patrón Boylan, 2001, 4.

38 Patrucco, 2005, 127.

39 Vargas Ugarte, 1981, IV, 110-111.

40 Idem.

41 Idem.

42 Tras el examen de una carta acusatoria contra el príncipe en el juicio de residencia que se le hizo, se conoce que Candiotti residía en Cádiz como corredor de lonja, pero era de origen veneciano. 


\section{CuAdro 2}

\section{MEMORIA DE LAS PERSONAS QUE DEVEN PASAR A YNDIAS CON EL PRÍNCIPE DE STO BONO VIRREY DEL PERÚ ${ }^{43}$}

\begin{tabular}{|c|c|c|}
\hline Miembros del séquito & Función/familiar & Lugar de origen \\
\hline El Príncipe de Santo Bono [sic] & virrey & Reino de Nápoles ${ }^{44}$ \\
\hline El Duque de Catrel de Sangro & hijo & \\
\hline D. Fabrizio Rufo & $\begin{array}{l}\text { mariscal de campo, } \\
\text { comendador }\end{array}$ & Nápoles \\
\hline D. Domingo Rufo & capitán de caballería & Nápoles \\
\hline D. Fernando Tinaguero & capitán de infantería & \\
\hline D. Virginio María Crista ${ }^{45}$ & caballero & Génova \\
\hline D. Melchor de Paz & secretario de cámara ${ }^{46}$ & Madrid \\
\hline D. ${ }^{\text {a } L u z i a ~ D e g h i n i ~}$ & mujer de D. Melchor de Paz & Venecia \\
\hline D. ${ }^{a}$ Theresa Mingo & criada de D. ${ }^{a}$ Luzia Deghini & Colmenar de Oreja \\
\hline D. Fernando Páez de la Cadena & $\begin{array}{l}\text { caballero de la orden de } \\
\text { Santiago, caballerizo del rey } \\
\text { y alférez mayor de Sanlúcar }\end{array}$ & Sanlúcar de Barrameda \\
\hline D. N. N. & $\begin{array}{l}\text { hijo de D. Fernando Páez de la } \\
\text { Cadena }\end{array}$ & Sanlúcar de Barrameda \\
\hline D. Pablo Argentini & & Ciudad de Rimini \\
\hline D. Juan Bauptista Piombini & & Ciudad de Bolonia \\
\hline D. Francisco Santa Cruz & secretario de $\operatorname{cartas}^{47}$ & Madrid \\
\hline D. Leonardo Toschi & doctor clérigo & Reino de Nápoles \\
\hline D. Fernando Antonio Ghedini & doctor & Bolonia \\
\hline D. Juan Masseno & doctor cirujano & Módena \\
\hline Estevan Masseno & hijo de D. Juan Masseno & Módena \\
\hline D. Joseph Rossi & secretario de $\operatorname{cartas}^{48}$ & Reino de Nápoles \\
\hline D. Jorge Torelli & mayordomo $^{49}$ & Génova \\
\hline
\end{tabular}

43 Copia de la memoria original que presentó el príncipe de Santo Buono y que se remite desde la Secretaría del Consejo de Indias a la Casa de la Contratación, Madrid, 11 de febrero de 1713, AGI, Contratación, 5468, n. 2, r. 12, f. 9r-10r. Se respeta la grafía original de los nombres y apellidos.

44 Lohmann indica que era oriundo de Génova, Lohmann Villena, 1945, 371.

45 Se plantea la duda sobre el apellido Crista, ya que puede tratarse del servidor Virginio María Gritta. Por su parte, Vargas Ugarte menciona como agregado a un criado llamado Virginio María Giota como caballerizo mayor del príncipe. Vargas Ugarte, 1981, IV, 111.

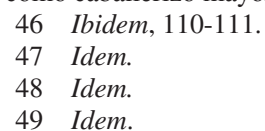




\section{CuAdro 2 (continuación)}

\begin{tabular}{|l|l|l|}
\hline \multicolumn{1}{|c|}{ Miembros del séquito } & \multicolumn{1}{|c|}{ Función/familiar } & \multicolumn{1}{c|}{ Lugar de origen } \\
\hline D. Francisco de Villegas & & Villa de Canillas \\
\hline D. Pedro de Bilbao la Vieja & & $\begin{array}{l}\text { Torresilla de los } \\
\text { Cameros }\end{array}$ \\
\hline D. Francisco Piombini & gentilhombre $^{50}$ & Bolonia \\
\hline $\begin{array}{l}\text { D. Francisco Xavier } \\
\text { Castellanos }\end{array}$ & & Madrid \\
\hline D. Juan Francisco de Foronda & & Asteguieta \\
\hline D. Joseph del Val & & Madrid \\
\hline D. Juan Miguel de Oteyça & & Sumbilla \\
\hline D. Juan Miguel de Laviano & & Pueyo \\
\hline $\begin{array}{l}\text { D. Elías Antonio Pérez de } \\
\text { Salcedo }\end{array}$ & & Madrid \\
\hline Esteban Mammoleti & & Ciudad de Urbino \\
\hline Domingo Paze & & Nápoles \\
\hline Jaime Tantanzi & & Roma \\
\hline D. Francisco María Barberi & abad & Roma \\
\hline Carlos Antonio Muzzi & & Bolonia \\
\hline Ángela Muzzi & mujer de Carlos Antonio & Bolonia \\
\hline Juan Crescimbeni & Muzzi & Ciudad de Asís \\
\hline Martino La Misa & & Bruselas \\
\hline Carlos Sirleti & & Reino de Nápoles \\
\hline Francisco Bilbao Rivera & & Francia \\
\hline Francisco La Villa & & \\
\hline
\end{tabular}

Fuente: Elaboración propia a partir de la documentación referenciada.

La esposa del príncipe, Constanza Ruffo, viajaba con su hija Julia Quintería y un séquito de veintitrés personas, donde figuraban, en primer lugar, siete criadas y, después, otros dieciséis miembros también bajo el término general de criados. Conocemos los nombres y lugares de procedencia de los criados y, en la mayoría de los casos, también se informa sobre la tarea de servicio específica asignada. Las mujeres representaban casi la mitad del séquito de la princesa, pues además de las criadas mencionadas, se

50 Idem. 
registraron tres mujeres como acompañantes del criado Teodoro Candiotti, en su papel de esposa, hija y criada, respectivamente.

Sobre las ocupaciones desempeñadas por las mujeres, solamente una de las criadas era registrada como lavandera, mientras las demás posiblemente ocupaban un estatus superior, como damas al servicio la princesa, al figurar con el tratamiento de doñas en la relación mencionada. En cuanto a los criados, sabemos sus funciones al detalle: caballerizo, mayordomo, capellán, maestre de capilla, ayuda de cámara, botiller, cocinero, lacayo y cuatro pajes. En realidad, consta en la memoria las funciones de servicio de todos los criados masculinos, exceptuando al mencionado Candiotti, pero que por información de Vargas Ugarte sabemos que iba en calidad de mayordomo. ${ }^{51}$

En cuanto a los lugares de procedencia de la «familia» de la princesa, ocupan un primer puesto los de origen español, seguidos de los naturales de Italia. Entre los españoles, había siete de Cádiz, tres de Madrid, uno de Toledo y otro más de Tarazona. Entre los italianos, tres eran napolitanos, uno de Turín, uno de Génova y uno más de Bolonia. De Flandes aparecen consignados tres miembros del séquito — dos eran criadas-y, de París, otros dos individuos, uno como botiller y otro como cocinero. De los oficios de mayor prestigio, destacamos el capellán y el maestre de capilla, ambos italianos, el primero de origen napolitano y el segundo natural de Bolonia.

En el séquito del príncipe de Santo Buono, que viajaba en compañía de su hijo mayor Marino, el duque del Castell di Sangro, figuraban además otros treinta y ocho miembros, mayoritariamente hombres. Encabezaban la lista el virrey y su hijo, seguidos de Fabricio Ruffo y Domingo Ruffo, ambos naturales de Nápoles, el primero mariscal de campo y comendador y, el segundo, «capitán de caballos». Otros personajes a destacar son Fernando Tinajero, capitán de infantería, y dos caballeros, Virginio María Crista - Virginio María Gritta—, oriundo de Génova, y Fernando Páez de la Cadena, que era caballero de la orden de Santiago, caballerizo del rey y alférez mayor, procedente de Sanlúcar de Barrameda. Este personaje se hizo acompañar de un hijo también de origen sanluqueño. Otros sujetos de nación italiana eran Leonardo Toschi, clérigo y natural del reino de Nápoles; Juan Masseno, cirujano de Módena, a quien acompañaba su hijo Esteban, y el abad Francisco María Barberí, de Roma. Por último, se conoce la

$51 \quad$ Idem. 
extracción francesa del cocinero, Francisco Lavilla. Así pues, quedaron en la memoria consignados los lugares de procedencia de los individuos registrados. Por sus orígenes, sobresalen los italianos sobre los españoles, siendo un total de veintiuno, de los cuales, seis eran naturales del reino de Nápoles; otros lugares destacados serían Bolonia, seguido de Génova, Módena, Roma, Venecia, Urbino, Rímini y Asís. De distintos lugares de la España peninsular figuraban catorce personas: de Madrid, Colmenar de Oreja (Madrid), Sanlúcar de Barrameda, Canillas, Torrecilla de los Cameros, Asteguieta (Alava), Sumbilla (Navarra), Pueyo (Navarra) y Antequera. Además, constaban un flamenco, natural de Bruselas, y el cocinero francés. Hemos de añadir que algunas personas anotadas figuraban como esposas, hijos o criados de otros personajes de la comitiva. Este fue el caso de Melchor de Paz, natural de Madrid, que llevaba consigo a su esposa, de origen veneciano, Lucía Deghini, y a la criada de esta, llamada Teresa Mingo y natural de Colmenar de Oreja; igualmente, el doctor de Módena, Juan Masseno, llevaba en su compañía al hijo nombrado Esteban, y el boloñés, Carlos Antonio Muzzi, viajaba con su esposa, registrada como Angela Muzzi.

Con base en las dos memorias mencionadas, observamos una comitiva numerosa dispuesta para el viaje al Perú, como parte de la corte del príncipe, donde se aprecia una composición casi a partes iguales entre italianos y españoles. Aunque tal equilibrio respecto al lugar de origen no se da si distinguimos entre el séquito del príncipe y el de la princesa, puesto que en la comitiva de Santo Buono viajaban un número superior de italianos. Una última consideración en este análisis cuantitativo es señalar el número superior de napolitanos en ambos séquitos sobre el resto de personas oriundas de otras partes de Italia. ${ }^{52}$ Como en otros casos, se observa que la condición de extranjero y el no contar con cartas de naturaleza no fue un gran impedimento ni para pasar a Indias ni, como veremos después, para ocupar cargos relevantes dentro de la casa virreinal. ${ }^{53}$

Cabe decir que, si bien ambas memorias presentan una relación de sesenta y cinco miembros repartidos entre los dos séquitos, a la luz de las informaciones recogidas sobre otras licencias de pasaje a Indias otorgadas antes de la partida del príncipe, la corte que llevó al Perú fue mayor. Se

52 Patrucco informa de unos 350 italianos presentes en el Perú para el siglo XVIII, y destaca de ellos el grupo de sirvientes y criados, cuya mayoría pertenecía al séquito de Santo Buono; dicha cohorte se nucleó en el palacio virreinal junto a otros allegados. Patrucco, 2011, 974-975.

53 El favoritismo del virrey y príncipe de Esquilache hacia los miembros de su séquito de origen portugués puede ser otro ejemplo. Sullón Barreto, 2018, 213-244. 
sabe que el viaje se retrasó al menos en una ocasión ${ }^{54}$ y que, en el ínterin, se otorgaron nuevas licencias para otros personajes que acompañaron al príncipe en la travesía, entre los que figuraban los nombres de Luis de Alarcón, ministro de Indias, y José Potau, alcalde de casa y corte. ${ }^{55}$ Fue entonces cuando también se autorizaba a Constanza Ruffo y a su hija Julia Quintería para viajar junto al príncipe. Dos licencias más se concedieron: una para el Conde de Bena, capitán de las guardias reales, quien recibía permiso para viajar con «sus baúles de ropa, matalotajes y dos criados», y la segunda para el confesor personal de Santo Buono, Juan Muñoz de la Plaza, clérigo regular de la congregación de los padres agonizantes, quien viajaría junto «con un compañero». Asimismo, se solicitaba a la corte la autorización para llevar un médico en el séquito, cuyo nombramiento recaía en la persona de Federico Bottoni.

Se debe añadir a tan nutrida corte una serie de personas de servicio que aún quedaban por confirmar en la lista de pasajeros. Así consta en la relación del séquito del príncipe: «en esta memoria faltan los nombres de otros dos Gentilhombres y tres Pages que están fuera; como también otro Cocinero con su Ayudante deel ${ }^{56}$ con su Ayudante, y de dos lacayos que se han de tomar de Cádiz pudiendo ser alguno de ellos casado, lo que se deve prevenir a quien ha de tomar el Ynforme». ${ }^{57}$

Vargas Ugarte menciona algunos de estos personajes agregados al príncipe:

Don Luis de Alarcón. D. José Potau, D. Melchor de Paz, su Secretario de Cámara, D. Francisco Santa Cruz, secretario de cartas, D. José Rossi, ídem, D. Teodoro Candioti, Mayordomo, D. Ignacio Domínguez, Camarero mayor, D. Fabricio Bártoli, caballerizo, D. Jorge Torrelli, mayordono, don Francisco Piombini, Gentilhombre, D. Federico Bottoni, médico de S. E., D. Juan Massano, Cirujano y, como agregados, el Conde de Bene, Don Virgilio María Giota, D. José Barberi y los PP. Agonizantes, Juan Muñoz de la Plaza y Juan Fernández, uno de los cuales era su confesor. ${ }^{58}$

Casi todos los citados se encuentran en la lista de pasajeros consultada, excepto Luis de Alarcón, José Potau, Jorge Cugurra, ${ }^{59}$ Federico Bottoni,

54 «QQ]ue el referido Príncipe de Santo Buono no pudo por sus achaques embarcarse en los navíos del cargo de D. Antonio de Echevers», AGI, Contratación, 5468, n. 2, r. 12, f. 2v.

55 AGI, Contratación, 5468, n. 2, r. 12, f. 3r-6v.

56 Espacio en blanco.

57 AGI, Contratación, 5468, n. 2, r. 12, f. 10r

58 Vargas Ugarte, 1981, IV, 110-111.

59 Licencia a Jorge Cugurra para pasar al Perú en compañía de dos criados, 13 de marzo de 1713, AGI, Contratación, 5467, n. 8. 
el conde de Bena y los padres Juan Muñoz de la Plaza — confesor del príncipe- y Juan Fernández, de los cuales tenemos constancia como «agregados» de la familia del virrey por las licencias posteriores mencionadas. ${ }^{60}$ Respecto a Federico Bottoni, hay que destacar su servicio como médico personal del virrey y la familia, así como el papel desempeñado durante la travesía para atender a la princesa de las fiebres que tuvo después del parto.

\section{Cuadro 3}

\section{NÓMINA DE AGREGADOS, NO INCLUIDOS EN LA MEMORIA CON LOS MIEMBROS DEL SÉQUITO}

\begin{tabular}{|c|c|}
\hline Agregados & Función/familiar \\
\hline Luis Tiburcio Caraccioli ${ }^{61}$ & hijo de corta edad, caballero de Malta \\
\hline Juan Constanzo Caraccioli62 & hijo nacido en la travesía \\
\hline D. Luis de Alarcón y Vargas & ministro de Indias \\
\hline D. José Potau y Olcina & alcalde de casa y corte \\
\hline D. Jorge Cugurra ${ }^{63}$ & diversas comisiones \\
\hline El conde de Bena & capitán de la guardia del virrey \\
\hline El P. Juan Muñoz de la Plaza & confesor del príncipe \\
\hline El P. Juan Fernández & padre acompañante de Juan Muñoz de la Plaza \\
\hline D. Federico Bottoni & médico personal de la familia del príncipe \\
\hline
\end{tabular}

Fuente: Elaboración propia a partir de la documentación referenciada.

Uno de los hechos más destacados y trágicos del traslado de la corte de Santo Buono al Perú fue la muerte de doña Constanza de Ruffo, quien falleció de fiebres puerperales tras el alumbramiento de su decimocuarto hijo. ${ }^{64}$ Su cuerpo fue sepultado en el monasterio de Santa Teresa de Cartagena de

60 AGI, Contratación, 5468, n. 2, r. 12, f. 2v-6v.

61 Rizo-Patrón Boylan, 2001, 4.

62 Idem.

63 Jorge Cugurra fue comisionado por Santo Buono para acabar con el comercio ilícito. AGI, Lima, 490 y 491. Posteriormente, fue demandado por sus procedimientos en dichas comisiones. AGI, Escribanía, 554B.

64 «La princesa Constanza Ruffo, hija del duque de Bragnara y sobrina del cardenal Tommaso Ruffo, se había casado a los trece años y al momento de embarcarse llevaba ya veintidós años de matrimonio y había tenido trece hijos y, al embarcarse en Cádiz, se hallaba nuevamente en estado interesante». Patrucco, 2005, 116. 
Indias. De esta forma, el virrey hizo su entrada en Lima ya viudo, acompañado por su hijo mayor Marino, duque del Castell di Sangro; su segunda hija, aún adolescente, Julia Quintería; el recién nacido, bautizado como Juan o Giovanni Constanzo, y otro hijo, aún niño, llamado Luis o Luigi Tiburcio, que no aparece mencionado en las memorias de pasajeros aludidas, del cual nos informa Rizo-Patrón. ${ }^{65}$

Así pues, una vez reunida toda la información acerca del séquito, otros deudos y criados agregados, además de personas de servicio que se pudieran tomar en Cádiz antes del embarque, la cifra de la corte virreinal de Santo Buono podía alcanzar fácilmente los ochenta o más miembros. No obstante, parece que esta corte no llegó a ser tan grande como la de Francisco de Borja, príncipe de Esquilache (1615-1621), compuesta por 174 personas, o la de Pedro de Castro Fernández de Andrade, conde de Lemos (1667-1672), que contó con 113 miembros en su séquito. ${ }^{66}$

\section{Deudos, criados y allegados en la corte virreinal}

La familia de un virrey, compuesta de parientes, criados y allegados, era casi siempre un asunto espinoso a la hora de gobernar con la máxima neutralidad requerida y, como señala Cañeque, la polémica existía tanto en el virreinato de Nápoles como en los virreinatos de la América española. ${ }^{67}$ La controversia aludía a la noción central sobre la liberalidad del gobernante y a las relaciones de patronazgo y clientelismo consustanciales a las figuras de los virreyes. Se trata, como indica el autor, de una cultura del don o de la gracia distribuida por los virreyes que, teóricamente, debía efectuarse de manera libre y gratuita, pero que en la práctica se vio muy determinada por las obligaciones que tenían estos vicesoberanos para con sus deudos, servidores y demás criados.

La figura del criado en la historia posee un carácter polisémico que, para el caso del flujo migratorio a Indias, conviene tener siempre muy presente, sobre todo ante el elevado número de individuos que bajo el término de criados pasaron a tierras del Nuevo Mundo. Se sabe que una buena

65 Sobre los hijos que quedaron en Europa, se sabe de «la hija mayor, Juana Irene, marquesa de Crebacore (nuera del príncipe de Masserano), Fernando (canónigo en Toledo), Juan Antonio, Jácome, Enriqueta, Josefa Antonio y Emilia. Previamente había fallecido otra de las hijas». Rizo-Patrón Boylan, 2001, 4-5.

66 Costa Vigo, 2017, 45.

67 Cañeque, 2017, 25. 
proporción — difícil de evaluar- de personas registradas por la Casa de la Contratación como tales eran, además, criados ficticios. Su inusitada presencia y el cuantioso pasaje que llegaba con cada virrey al Perú levantó la crítica desde fechas relativamente tempranas, como la expuesta por el jurista Juan de Matienzo. ${ }^{68}$ Tras los reproches a tan elevada cifra de asistentes para los virreyes, se encontraba el recelo a las más que previsibles recompensas que recibirían esos criados, y las infinitas posibilidades que tenían para medrar. La Recopilación de las Leyes de Indias destinó numerosos artículos a frenar los abusos que generaban esos vínculos e intereses personales de los criados con los virreyes. ${ }^{69}$

La distribución de mercedes y beneficios entre los miembros de los séquitos de los virreyes se traducía, en su mayoría, en premios en forma de oficios, lo que generó un gran dilema al poder regio y a los habitantes de las colonias de Ultramar. Para el monarca, significaba un mal uso de las prerrogativas que gozaban los virreyes en América y se interpretaba, pues, como un motivo de debilitamiento del poder regio. Para los habitantes del Nuevo Mundo, y de manera especial para los criollos, el patronazgo y la liberalidad del vicesoberano fueron causas permanentes de su discriminación y exclusión en el reparto de mercedes. Por el contrario, estos gobernantes al frente del solio virreinal defendían el principio de discrecionalidad que le confería su cargo para otorgar gracias a individuos que pudieran ser de su círculo más próximo o personal. De esta forma, la generosidad de un gobernante, entendida esta como una liberalidad obligatoria y como un asunto estricto de justicia, quedaba más que cuestionada. ${ }^{70}$

Tal problemática explica que una corte virreinal se convirtiera —en palabras de Suárez- en un «espacio de negociación por excelencia», ${ }^{71}$ porque cabe tener presente que el patronazgo ejercido por los virreyes, con su red privada de parientes, criados y allegados, se vería de alguna forma frenado y mediatizado por otras instancias de poder como podía ser el propio Consejo de Indias y por otros mecanismos de la época como era la venta de cargos; una venalidad que colocó a los criollos peruanos en numerosos puestos de la administración indiana como, por ejemplo, en las magistraturas de las audiencias americanas. Es, por este motivo, que un abuso de autoridad en lo referente a distribución de mercedes y oficios podía derribar

68 Porro Girardi, 1995, 1233.

69 Ibidem, 1237.

70 Cañeque, 2017, 32.

71 Suárez, 2017, 72. 
a un virrey, como pasó con el virrey conde de Castellar. Su política de reparto de mercedes y dádivas entre parientes y criados causó la indignación de los beneméritos y el enojo de la corte madrileña, y concluyó con su destitución en el año $1678 .{ }^{72}$ Según Suárez, después del gobierno de Castellar, se produjo un viraje en la política real al tratar de mermar el amplio margen de maniobra de que disponían los virreyes. Otro freno al reparto de cargos en manos de los virreyes sería la gran venalidad de los oficios producida entre 1687 y 1712 .

Estos hechos sirven de antesala a la llegada de Santo Buono al Perú. Aunque la época de mayor venalidad había pasado, su patronazgo a ejercer en el solio virreinal iba ser mirado con lupa. Por otro lado, la red clientelar en torno a criados y deudos se había fraguado con los preparativos del viaje a las Indias. Recordemos que quienes encabezaban la memoria de personas que acompañaban al príncipe y a su primogénito en el séquito personal eran dos sujetos principales, Fabricio Ruffo, mariscal de campo y comendador, y Domingo Ruffo, capitán de caballería, ambos naturales de Nápoles. Junto a los Ruffo, como deudos de la princesa, debemos mencionar a Jacinto Fiesco, conde de Bena de Maserán, y hermano del hijo político del príncipe, el marqués de Crevencour, quien ocupaba el cargo de capitán de la guardia del virrey. ${ }^{73}$ Este personaje, como veremos más adelante, también será mencionado en los cargos hechos a Santo Buono durante su residencia. ${ }^{74}$

Entre los miembros de su corte, también se conocen las acciones poco lícitas de tres de ellos para su enriquecimiento personal. Se trataba del caballerizo mayor Virginio María Giota - Gritta-, del secretario Melchor de Paz y del mayordomo Jorge Torelli, que se lucraron con sus tratos comerciales con un navío de nacionalidad francesa, ${ }^{75}$ hecho que figuraría en el juicio de residencia del virrey, donde finalmente no constaron cargos importantes contra su gobierno, salvo el de haber actuado con lenidad con los contrabandistas e implicados en el comercio ilícito, ${ }^{76}$ aparte de otros asuntos que mencionaremos después.

Tenemos noticias destacadas del abad romano José María Barberí, quien aparece en la memoria de las personas que viajaban en compañía de Santo Buono. A Barberí se le atribuye una denuncia hecha contra los

72 Ibidem, 69-95. $2005,127$.

También fue nombrado como capitán de caballos de la compañía de palacio. Patrucco,

$74 \mathrm{Al}$ virrey se le acusaba de haber pagado en exceso al capitán de su guardia. Idem.

75 Vargas Ugarte, 1981, IV, 111-112.

76 Ibidem, 118-119. 
excesos y abusos de autoridad perpetrados por el arzobispo y de nuevo virrey del Perú Diego Morcillo. ${ }^{77}$ Ricamente documentado por Moreno Cebrián, conocemos el papel que jugó el personaje Barberí en la confección de una Relación escrita en Lima en enero de $1722,{ }^{78}$ donde se critican las circunstancias de desorden en que vivía el clero peruano, siendo el arzobispo Morcillo uno de los prelados que salía peor parado. Aunque el memorial partía del círculo del anterior arzobispo de Lima, Antonio de Soloaga, según Moreno Cebrián se puede considerar al abad romano como el autor material del documento. El personaje Barberí figura como uno de los familiares más influyentes de la corte de Santo Buono; cabe destacar la amistad que fraguó nada más llegar con el arzobispo Soloaga, y los numerosos contactos y misivas que dirigió al nuncio de Madrid y al Sumo Pontífice durante su paso por Indias. ${ }^{79} \mathrm{El}$ carácter particular de este personaje y sus maquinaciones palaciegas reflejan un cuadro de intrigas y enredos en la corte del virrey potenciado por este abad de origen romano. ${ }^{80}$

En el círculo más próximo a Santo Buono mencionamos también a José Potau y a Luis de Alarcón. El primero, perteneciente a una familia de juristas de origen catalán, se doctoró en derecho en el colegio de San Clemente de Bolonia. ${ }^{81}$ La carrera de este colegial se inicia en Italia con diversos puestos, entre los cuales destacaría el nombramiento que obtuvo

77 Tras su breve paso como virrey interino, al ser relevado por Santo Buono, sería nuevamente virrey del Perú entre enero de 1720 y mayo de 1724, acumulando en su persona, a partir de 1723, el nombramiento de arzobispo de Lima.

78 «Relación que el arzobispo de Lima, Antonio de Soloaga, hace a Su Santidad, en exoneración de su conciencia, tocante a los abusos y escándalos introducidos en estos Reinos, según consta de los autos de las visitas de su diócesis y de algunos procesos y recursos presentados en este tribunal eclesiástico para que Su Santidad se sirva disponer con el Rey Católico las providencias más convenientes a su reforma», AGI, Lima, 413. Referencia en Moreno Cebrián, 2003, 224.

79 Moreno Cebrián resalta el carácter fuertemente antirregalista de este individuo. Ibidem, 262.

80 «Era acérrimo detractor de todo lo español y pasaba por ser doctor en leyes, aunque tenía por única actividad el dedicarse a la composición de libelos y pasquines. Tomaba apunte de todo cuanto sucedía en especial todo lo que se relacionase con intriga palaciega que comunicaba a la metrópoli. Se burlaba de las decisiones de Morcillo aunque no dejaron de caer en sus escritos los mandatos de su patrón Santo Buono a quien le había dedicado una sátira titulada El lindo gobernador, donde se criticaba acremente su gestión y, quizá por temor a sus viperinos comentarios, no hizo nada en su contra el noble napolitano. Su suerte cambiaría al llegar el Virrey Arzobispo Morcillo. Lohmann piensa que sería este el autor de la sátira El Templo de la Fama, obra que a juicio de un contemporáneo era "muy denigratoria contra el príncipe que nos gobierna (Morcillo)" y que se debía al círculo de los allegados de Santo Buono. El fin de esta aventura fue la pesquisa hecha en la casa de Barberi, en 1722, donde se encontró ingentes cantidades de indicios de su actividad de libelista y, por lo cual, por "mendaz, falsario y caprichoso" fue sentenciado al destierro en el presidio de Valdivia por seis años, pena totalmente desmedida». Patrucco, 2005, 132.

81 Cuart Moner, 1998, 172. 
del virrey de Nápoles, el marqués de Villena, don Juan Manuel Fernández Pacheco, como oidor de Téramo. Posteriormente, fue trasladado de la administración italiana a España como oidor de la audiencia de Sevilla y, después, fue nombrado alcalde de casa y corte. Su marcha a las Indias está relacionada con un reducido núcleo de colegiales de San Clemente que, en el siglo XVIII, pasaron a ocupar diversos cargos, especialmente en audiencias americanas. Aunque Cuart señala la posibilidad de haber pasado, antes de llegar al Perú, por la audiencia de México, casi con toda seguridad viajó con el séquito de Santo Buono rumbo al Perú, dada la licencia expedida como familiar agregado del virrey. También hay constancia de una carta escrita por el propio Potau desde Madrid, en 1712, donde da cuenta de haber sido designado «ministro» del virrey del Perú. Posteriormente, el juicio de residencia al predecesor de Santo Buono, el obispo de Quito Diego Ladrón de Guevara, sería encargado a Potau, cuyo rigor en el procedimiento ${ }^{82}$ y en la sentencia dictada llevaron a calificar su comisión en dicha residencia de desproporcionada. ${ }^{83}$ La estrecha colaboración de Potau con el virrey vino sin duda determinada por el nexo previo en tierras italianas, lo que explicaría aún mejor ese nombramiento de Potau como juez comisionado para diversos asuntos en el Perú.

Luis Ambrosio de Alarcón y Vargas, de origen sevillano, fue miembro del colegio de Santa María de Jesús y se licenció en derecho canónico por la universidad de Sevilla; también fue estudiante de la misma materia en Salamanca. Tal vez, el vínculo de este ministro con Santo Buono se fundamente en el hecho de que asistiera igualmente al colegio mayor de San Clemente de Bolonia y de que, antes de ejercer en la audiencia de Sevilla y desempeñarse como profesor en la universidad de esta ciudad, sirviera como oidor en la corte de Santa Clara en Nápoles. Con la Guerra de Sucesión se vio obligado a huir, y Felipe V, en compensación, lo nombró alcalde de la sala de casa y corte. Posteriormente, por decreto de 19 de noviembre de 1712, Alarcón fue nombrado ministro del Consejo de Indias con instrucciones de acompañar al Perú al virrey recién nombrado, el príncipe de Santo Buono. Entre los nuevos encargos, tuvo la misión de la superintendencia de la mina de Huancavelica, por la cual fue sometido a una investigación instigada por los enemigos de Santo Buono, los oidores Miguel Núñez y Juan de

82 Las diligencias del proceso se dilataron hasta el año 1718 bajo el mandato de Caracciolo. Vargas Ugarte, 1981, IV, 108.

83 Ibidem, 108-109. 
Echevarría. ${ }^{84}$ Por nombramiento de 10 de enero de 1720, Alarcón se convirtió en oidor de la audiencia de Lima. En 1723 renunció a su puesto en la citada audiencia para regresar a España y servir en el Consejo de Indias. ${ }^{85}$ $\mathrm{Su}$ juicio de residencia como superintendente de la mina de Huancavelica estuvo a cargo del mismo juez de residencia de Santo Buono, Juan Pérez de Urquizu.

Virginio María Gritta figura como otro de los servidores destacados y «señor noble de la República de Génova», a quien se otorgaría poder general cuando estaba próxima la partida de Santo Buono para los reinos de España. ${ }^{86}$ La misma entrega de poder a Gritta hizo el primogénito de Santo Buono, el duque del Castell di Sangro, cuando marchó rumbo a Venecia, al lugar de sus estados en la provincia de Bouzá. ${ }^{87}$ Gritta era caballerizo mayor del virrey y, sin duda, otro de los personajes más influyentes de la corte virreinal. ${ }^{88}$ Su nombre también aparece en los papeles del juicio de residencia, acusado de hacerse con el abasto de la carne y manteca para la ciudad de Lima.

Las numerosas y tan destacadas funciones ejercidas por algunas de las personas que integraron su séquito promovieron la elaboración de un Reglamento para establecer varios protocolos que regirían la casa del virrey con una descripción de los puestos principales. ${ }^{89}$ Mencionamos, según la importancia otorgada en el Reglamento, al secretario del virrey, cuyo cargo recayó en la figura de José Rossi, de origen napolitano, y, en segundo orden, a los mayordomos. El mayordomo mayor Teodoro Candiotti, que viajó con varios familiares en el séquito de la princesa, aparece mencionado en la residencia del virrey por un asunto de comercio ilícito. Mayordomos

84 Moreno Cebrián, 2003, 270.

85 Burkholder y Chandler, 1982, 6-7. Burkholder, 1986, 4-5.

86 Igualmente, se nombraban para el poder al secretario Melchor de Paz y a Bernabé Felipe de Aragón. Patrucco informa que de estos documentos se extrae sustancial información sobre los gastos del viaje y el establecimiento de la familia del virrey en Lima, cubiertos básicamente con las rentas del mayorazgo de Marino Caracciolo, padre de Santo Buono. Codicilio testamentario y poder general en Archivo General de la Nación de Lima (AGNL), Sección Notarial, E.: Pedro de Espino Alvarado, Protocolo, 261, 17 de enero de 1721, f. 86r-93v; y 19 de enero de 1721, f. 101r-101v. Citado en Patrucco, 2005, 120-121.

87 Ibidem, 125-126.

88 Con estas palabras Patrucco describe el poder ejercido en Lima: «Ya en Lima, se puede ver que gozaba de la entera confianza del virrey y, por ello, desde 1718, tenía alquilado, aparte de su casa en la calle de Núñez, un rancho en Miraflores al lado de la iglesia de dicho pueblo en donde solía recrearse el virrey y en el que se realizaban algunas obras de teatro. En razón de su puesto, de ser caballero noble de Génova, y de su habilidad documentaria será la persona que represente a gran parte de los allegados del virrey, al momento de regresar a Europa». Ibidem, 130.

89 Reglamento para el gobierno de la Casa de Su Excelencia Príncipe de Santo Buono, Balzo, $1965,131$. 
eran también Fabricio Bartoli, ${ }^{90}$ el italiano de la ciudad de Rimini, Pablo Argentini, ${ }^{91}$ y Jorge Torelli, quien fue destituido por el propio Santo Buono ante un asunto turbio relacionado con el comercio ilegal y extranjero. Hasta las funciones de los pajes eran descritas en el Reglamento para el buen gobierno de la casa virreinal; mencionamos de nuevo a los pajes Candiotti, Francisco, Rodrigo y Pedro, parientes del mayordomo mayor. De la memoria de familiares que viajaron en los dos séquitos, informa Patrucco de otros sirvientes que contribuyeron a la transformación de la corte y la ciudad de los Reyes según las costumbres y tradiciones de la cultura itálica. ${ }^{92} \mathrm{El}$ hecho de que la responsabilidad para la administración de la casa virreinal recayera en servidores de la plena confianza del virrey contaba ya con una larga tradición en la corte virreinal limeña. ${ }^{93}$

\section{El juicio de residencia}

La primera comisión para tomar residencia al príncipe fue señalada por vía reservada el 11 de enero de 1719, a cargo de Miguel Núñez de Sanabria como presidente, y los oidores Pablo Vázquez de Velasco ${ }^{94}$ y Miguel de Ormaza Ponce de León, el cual, tras su fallecimiento, fue sustituido por Juan de Echevarría Zuloaga. ${ }^{95}$ Las pesquisas y dudas acerca de su gobierno fueron dirigidas, principalmente, al cumplimiento de diversas órdenes emitidas para combatir el contrabando y otras acciones derivadas del comercio prohibido con embarcaciones extranjeras, así como por las noticias que se tenían sobre los negocios del caballerizo del virrey, Virginio María Gritta, que tomó el abasto de la carne y manteca del distrito de Lima, y de las comisiones de Joseph Potau y de Luis Ambrosio de Alarcón, uno en la residencia al obispo de Quito y el otro por su empleo en Huancavelica. Igualmente, se informaba de los procedimientos abusivos del servidor del virrey Jorge Cugurra en la comisión que tuvo en Guamanga. También indicaba la comisión hacer averiguaciones sobre la provisión de unos corregimientos.

90 Según Patrucco, era Fabricio Barroli, a quien tal vez le asignaron el cargo de veedor que señalaba el Reglamento. Patrucco, 2005, 129.

91 Ibidem, 122.

92 Ibidem, 133-134.

93 Véase la figura del valido materializada en la persona de Martín de Acebedo durante el virreinato del príncipe de Esquilache. Villarreal Brasca, 2018, 141-165.

94 Vázquez de Velasco sería reemplazado al fallecer por el oidor José Santiago de la Concha.

95 Primera residencia del Príncipe Santo Bono, virrey, 1719, AGI, Lima, 487. 
Cabe señalar que en el juicio estuvieron enfrentados los oidores Echevarría Zuloaga y Vázquez de Velasco, quien ofició como aliado del príncipe para advertirle de los pasos de los visitadores y cohechar a los testigos. El interrogatorio formulado con doce preguntas, y que lleva fecha de 15 de marzo de 1720, fue objeto de crítica por parte de Echevarría Zuloaga, que propuso «un apuntamiento de los artículos y expresiones que se podían añadir».96

Una gran parte del apuntamiento de añadidos iba dirigido a la investigación de los allegados del virrey, donde se introducían preguntas aclaratorias como las siguientes: ${ }^{97} 1$. Las razones por las que el virrey no recibía ni daba audiencia a los ministros, lo que permitía que sus criados vendiesen las audiencias y, por esa razón, llamaban a su camarero Ignacio Domíngue ${ }^{98}$ «cancerbero»y otros «macutela». 2. Que sus criados hicieran negocios actuando como agentes de causas y memoriales para que se los pagasen. 3. Sobre el mal gobierno del virrey «sin consultar a los experimentados y sólo confería con los ministros acompañados que trajo de España y carecían de conocimiento y experiencia de la tierra y de los habitadores de ella y de sus particulares negocios y prácticas». 4. «Iten si saben que al mismo tiempo que gastaba tanta autoridad, se rosaba con la gente más perjudicial y con sus ayudas de cámara, dejándose tratar con una llaneza desautorizada y ajena de su representación y grado». 5. Averiguar si no castigó los pecados públicos y consintió a las «mujercillas», y cuando se quiso moderar trajes y calesas escandalosas, lo embarazó por contemplación de su ayuda de cámara Domingo Pache. ${ }^{99} 6$. «Iten si saben que en las salidas que hacía al campo frecuentemente, se trataba con la misma llaneza y se repetían los mismos juegos y abusos en todo género de gentes, y en una de aquellas ocasiones, introdujo el duque su hijo una congregación que llamó religión del tocaísmo para fines malos y que el pueblo los estimaba por escandalosos, y el mismo virrey apoyaba esta perversa introducción, poniéndose a dictar particulares constituciones y reglas en orden a ellas, y que nunca reparó en el mal ejemplo que daban, su hijo, Conde de Bene, allegados y criados ni en las vejaciones y extorsiones

96 Apuntamiento de añadidos que llevó el oidor a la junta con los otros dos jueces, y donde, según informó Echevarría, Vázquez de Velasco lo reprobó todo «con tanto empeño» que se desestimó su voto, AGI, Lima 487.

97 Solo se extractan aquellas preguntas que hacen referencia a los deudos, ministros y criados del príncipe.

98 Según Vargas Ugarte, era camarero mayor del virrey; en la memoria del séquito de la princesa es registrado como caballerizo. AGI, Contratación, 5468, n. 2, r. 12, f. 7r.

99 En la memoria de integrantes del séquito del príncipe queda registrado como Domingo Paze, natural de Nápoles. AGI, Contratación, 5468, n. 2, r. 12, f. 9v. 
que ellos hacían a los vasallos, para que les contribuyesen por todos medios». 7. Averiguaciones sobre el daño realizado a los indios haciendo interés y granjería de sus criados, especialmente de Francisco de Alarcón, quien aplicó nuevos impuestos y contribuciones para despachar memoriales, de lo que se quejó el fiscal protector. 8. Si favoreció a Alarcón ${ }^{100}$ en Huancavelica y perjudicó con ello la Real Hacienda. 9. Se apuntaba si solo pagaba a los soldados de a caballo y guardias de alabarderos, descuidando el resto de acreedores de la real hacienda, porque eso se convertía en beneficios para el duque, su hijo, y el conde de Bena, capitanes de ambas guardias. 10. Que los allegados, el duque, el conde de Bena, Virginio María Gritta y otros tenían tiendas públicas aunque ponían en ellas a sus mozos y comerciaban con los corregidores. 11. Averiguación de los negocios realizados con el corsario Martinet $^{101}$ y si este hacía grandes regalos a la familia y allegados. 12. Si abusaba de la justicia pidiendo componerse con los encausados por medio de su ministro José Potau. 13. Si dio corregimientos por dádivas y sus allegados hacían que estos comerciaran mulas para ellos.

Fueron catorce los cargos que resultaron de la residencia practicada por los jueces. ${ }^{102}$ De estos cargos, en relación a sus servidores y allegados, habían sido muy cuestionados el duque del Castell di Sangro por la casa de juego que tenía, el criado Francisco de Alarcón por los perjuicios ocasionados a los indios, su mayordomo Teodoro Candiotti, quien recibió una suma de 600.000 pesos, junto a otros allegados del virrey beneficiados con unos 400.000 pesos. Algunos cargos hacían referencia a los obstáculos de los criados del virrey a la acción de la justicia o al haber priorizado Santo Buono los salarios para su guardia a caballo, antes que los de las milicias del reino y del presidio del Callao. Otras acusaciones hacían referencia a dejadez de funciones, a varios excesos y escándalos contra las buenas costumbres, a fraudes en el beneficio de corregimientos o a permitir el contrabando

100 Se trata del ministro Luis Ambrosio de Alarcón, nombrado superintendente de la mina de Huancavelica.

101 Para librarse la Corona de los contrabandistas en el Pacífico, se organizó una escuadra dirigida por el corsario Jean Nicol Martinet con tres navíos de su propiedad y tripulaciones francesas. Gómez, 2006.

102 Los cargos se firmaron el 6 de septiembre de 1720, notificados a la parte el día siguiente y sacados en traslado por el oidor Echevarría Zuloaga, quien escribió el 8 de noviembre de 1720 remitiendo informe de la residencia con la certificación de los cargos adjunta al marqués de Grimaldo. Daba cuenta de todas las incidencias de la residencia, empañada por la actitud de Vázquez de Velasco. Añadía, además, varias curiosas «certificaciones» del escribano Urtasu, entre las cuales indicaba el haber sido presionado y obstaculizado por Vázquez de Velasco y de cómo este se enfrentaba a Echevarría Zuloaga, presionaba a testigos y agredía a los que entendía declaraban en contra. AGI, Lima, 487. 
con los franceses; cargos donde observamos numerosas similitudes con los imputados a su antecesor, el marqués de Castelldosrius, enunciados de forma secreta en abril de 1709 por un ministro de Indias. ${ }^{103}$

En el alegato de respuesta a los cargos que se formularon en esta residencia, interesa de forma muy particular el descargo que hizo el procurador Pérez de Guzmán, cuya defensa se encuentra impresa en setenta y cinco fojas. ${ }^{104} \mathrm{El}$ impreso responde, sin duda, a un esfuerzo de propaganda reivindicativa del príncipe en defensa de su honor y buen gobierno, cuyo objeto de impresión iba más allá del ámbito judicial, y que, como otros alegatos impresos de la época, contenía un valor agregado de carácter extrajudicial. En este tipo de defensas jurídicas o porcones la cuestión del honor era una de las claves para desear la reconstrucción de un pleito o juicio a través del relato y el discurso de la defensa. ${ }^{105}$

Llegado a conocimiento del Consejo de Indias la residencia y los malos procedimientos que la rodearon, se decidió declararla nula y se pidieron nuevas diligencias para la continuación del juicio. Este correría a cargo del oidor Juan Pérez de Urquizu, siendo realizado entre el 2 de enero de 1720 y el 23 de abril de $1722 .{ }^{106}$ Cabe preguntarse por los motivos del reemplazo de Echevarría Zuloaga por el nuevo juez, y aunque no conocemos la causa exacta puede intuirse - muy presente en el apuntamiento al interrogatorio de la primera residencia- el conservadurismo del oidor y su fuerte rechazo a las innovaciones extranjerizantes del gobierno santobuonista. Este pudo

103 Sáenz-Rico, 1978, 119-135. La oposición criolla «le acusaba de ser hombre disoluto, de no haber celebrado suficientemente el nacimiento del Príncipe, de connivencia con el comercio francés y de venalidad, en su beneficio y de sus familiares, en la concesión de cargos públicos», en Sala i Vila, $2004,47$.

104 «Pedro Pérez de Guzmán, en nombre del Excelentísimo Señor Príncipe de Santo Buono, en los autos de su residencia del tiempo que exerció los cargos de Virrey, Gobernador y Capitán general de estos Reynos, y lo demás aducido, respondiendo al traslado de los catorce cargos, que se han deducido, y formado de la sumaria secreta», en John D. Rockefeller, Jr. Library, Brown University, microfilm, FHA 237.9.c.2. También para el descargo y los instrumentos numerados de la defensa, véase el segundo cuaderno de la residencia, AGI, Escribanía, 552A, f. 118-184 y f. 191-426.

105 Un análisis detallado del documento, que por su extensión no puede ser incluido en este trabajo, se encuentra en una fase preliminar de estudio bajo la óptica del valor de los porcones, línea de investigación adscrita al proyecto I+D titulado «Los usos sociales de las defensas jurídicas: publicación y circulación de los porcones en el Antiguo Régimen».

106 Residencia al príncipe de Santo Bono, virrey del Perú, por Juan Pérez de Urquizo, 1719 y 1722, AGI, Escribanía, 552A, B y C, 553A y B, 554 B. Asimismo, Moreno Cebrián informa sobre el segundo juicio de residencia en AHNM, Consejos, 21308, exp. 4; y también, para Chile, las informaciones secretas encargas al oidor Ignacio Fausto Gallegos en Archivo Histórico Nacional de Chile (AHNCH), Santiago, Real Audiencia, vol. 1747, pieza 1, y al oidor y alcalde de corte de la Real Audiencia de Santiago, Martín de Recabarren y, en su defecto, al oidor Juan del Corral Calvo de la Torre en AHNCH, vol. 2034, pieza n. ${ }^{\circ}$ 25. En Moreno Cebrián, 2003, 263. 
ser un motivo fundamental para apartarlo como juez ante la escasa imparcialidad que mostró en la residencia practicada. Unos «justos motivos» señalaron la destitución de su plaza de oidor, ejecutada en enero de 1721, en la que sería restituido en abril de 1723 pero sin el asiento y antigüedad debida. Echevarría, en un escrito de súplica elevado al rey, una vez restablecido plenamente en su cargo, se quejaba de los sueldos que dejó de cobrar por una suspensión injusta «en virtud de secretos informes del virrey». Probablemente, los informes eran del virrey Santo Buono. ${ }^{107}$

Cuando se ordenó la continuación de la residencia, salieron a la luz otros papeles contra Santo Buono que ya habían llegado al Consejo en años anteriores, incluso antes de su salida del solio virreinal. De ellos destacamos las cartas de Jorge Cugurra, otro servidor agregado a la familia del príncipe en el viaje de ida al Perú. Cugurra, que había sido gobernador de la provincia de la Gallura de Nuoro Orani y Biti, del reino de Cerdeña, presentaba todo un memorial de agravios en sus cartas contra el príncipe que pasamos a mencionar. ${ }^{108}$ Aunque recibió una ayuda de costa de dos mil pesos para acompañar a Santo Buono -igual que Alarcón y Potau—, se quejaba del continuo «desvío de atenciones» del príncipe a su persona y de la marginación que sufrió en los empleos que dispuso el virrey a favor de los «pedagogos que traía». Después de solicitar varios empleos e incluso permiso para retornar a España - todos ellos denegados-, fue comisionado para la inspección del comercio ilegal y del contrabando en la ciudad de Guamanga y el Cuzco. Su llegada a Guamanga, el 10 de septiembre de 1717, provocó — según sus escritos- un «tumulto y sublevación popular de más de tres mil hombres mestizos e indios capitaneándolos clérigos y frailes en número de más de cincuenta dellos y por general fray Joseph de Hiraola de la orden de San Francisco y confesor del obispo de Guamanga». ${ }^{109}$ Por los sucesos de Guamanga, Cugurra formó auto y proceso ${ }^{110}$ que envió al virrey. Sin embargo, el asunto, tras varios altercados más y otras acusaciones, concluyó con su destitución, por lo cual Cugurra pidió ser restituido a los reinos de España. Su última queja era haberle negado una ayuda de costa para sacarlo de su «cautiverio». Se lamentaba del estado de ruina en que se hallaba, mientras otros, decía, habían hecho «granjería del ministerio». Así, señalaba lo que

107 Solicitud de Juan Bautista Echevarría y Zuloaga, 1726, AGI, Lima, 438, f. 4.

108 «Autos originales que se remiten al real Consejo de Indias sobre el reconocimiento que hizo el gobernador don Jorge Cugurra de las cartas que escribió a SM». Cartas de 24 y 25 de marzo de 1718, AGI, Escribanía, 553A, pieza 4.

109 «Autos originales...», AGI, Escribanía, 553A, pieza 4, f. 3v.

110 El cuadernillo completo se encuentra en AGI, Lima, 487. 
sigue sobre varios destacados servidores del príncipe: Joseph Potau en un tiempo había reunido 100.000 pesos efectivos en moneda y 20.000 pesos en alhajas de plata y oro; Luis Ambrosio de Alarcón, en Huancavelica, en un año había granjeado 90.000 pesos; el secretario Melchor de Paz pasaba de 80.000 pesos lo que había recogido; Virginio María Gritta, «un mozo ginovés caballerizo del virrey», llegaba a más de 50.000 pesos lo granjeado; y Teodoro Candiotti, un corredor de lonja de Cádiz que trajo el virrey con toda su familia y era su mayordomo, de nación veneciano, y quebró en Cádiz, «vive con magnificencia de mucha grandeza».

En la segunda carta prosigue el enconamiento, donde tildaba al virrey de «ministro encantado» por no dar audiencias ni despachar, y de nuevo cargaba las tintas contra varios de sus servidores. Acusaba de enriquecimiento al virrey, a su primogénito y a José Potau. Sobre Alarcón en Huancavelica, decía que se embolsaba parte del quintal del azogue que había de pagar a los mineros, motivo por el cual estos eran más proclives al contrabando. De los tumultos en Guamanga, criticaba a varios oidores y fiscales como protectores de los sublevados, entre ellos a Vázquez de Velasco, ministro aliado del príncipe. De los beneficios en cargos, denunciaba las distribuciones, con las destituciones correspondientes, del corregimiento de Cochabamba para el secretario del virrey, Francisco de Santa Cruz, y del corregimiento de Sica Sica para su criado napolitano, Joseph Rossi, que, sin embargo, servía Juan Manuel de Otaiza —miembro del séquito-, en razón de la extranjería de Rossi. Sobre Potau, delataba las componendas que hacía con su compatriota catalán Josep Martorell, a través de su cargo de comisionado contra el contrabando. Y añadía «últimamente todos estos ministros viven de manera como si no hubiera dios y como si VM no fuera el amo y dueño desta hacienda y como que no han de dar cuenta dello. Porque ese virrey pretende retirarse a Roma y componer con plata los intereses de su casa».

Ambas cartas motivaron la toma de declaración a Cugurra, ordenada por el juez Urquizo el 19 de septiembre de 1724. Aunque reconoció como suyas las cartas, Cugurra se desdijo de mucho o explicó haberlo expresado en otros sentidos, visto lo cual, el juez informó no haber cargo alguno para el virrey por lo suscrito en las cartas, el 1 de mayo de 1725. Surge, pues, la duda razonable acerca del cambio producido en aquella declaración. Tal vez fuera cierta la idea que había deslizado el anterior juez, Echevarría Zuloaga, sobre el temor que sentía el propio Cugurra por las averiguaciones que, dentro de la residencia, se hacían para ver si cometió excesos en la comisión de Guamanga. 
Ordenada la continuación de la residencia, esta corrió a cargo del oidor Juan Pérez de Urquizo y los alcaldes del crimen Miguel de Gomendio y Javier de Salazar. ${ }^{111}$ En la Instrucción dada se señalaban los capítulos principales de la investigación, donde se reproducía gran parte de lo ya ordenado en la primera residencia. Y en lo relativo a los servidores y deudos del príncipe, las pesquisas debían centrarse en la provisión de algunos corregimientos y, en líneas generales, si los criados y allegados del virrey habían tenido tratos y contratos con ropas y otros géneros extranjeros. Uno de los capítulos donde la Instrucción puso mayor énfasis se refiere a la averiguación sobre el cumplimiento de las órdenes realizadas al jefe de la escuadra Martinet, al intendente o veedor general Gabriel de Lacunza ${ }^{112}$ y al propio Santo Buono, para la incautación de la carga que llevaban seis barcos extranjeros fondeados, uno en el puerto de Cobija y cinco en el de Arica, cuál fue el destino del género requisado, qué valor exacto suponía — se estimaba en unos cuatro millones de pesos- y si aquellos artículos habían sido rematados en su justo precio. Aquí, de nuevo, se preguntaba si algún criado, allegado, mayordomo o servidor del virrey había intervenido en la venta fraudulenta relativa a la ropa y al género de la China. Las veintiséis preguntas del interrogatorio ${ }^{113}$ seguían el tenor de los capítulos de la Instrucción y solo agregaba una pregunta relativa a los sucesos de Guamanga. ${ }^{114}$ En los pliegos de las preguntas se inserta una memoria de los agregados que trajo el príncipe, entre los cuales aparecen nuevos individuos, aparte de los incluidos en las dos memorias relativas a los séquitos. Divididos en cuatro categorías, la nueva memoria consigna como agregados, familiares, gentiles hombres y pajes los siguientes:

Agregados: Conde de Bena, Virginio Mariagrita; Familia de SE: Melchor de Paz secretario de cámara, Francisco de San Cruz secretario de cartas, despedido en 1717, Joseph Rosi secretario de cartas, Teodoro Candiote mayordomo, Ignacio Domínguez camarero mayor, Fabricio Bartoli caballerizo, Jorge Toreli mayordomo, despedido 28 de noviembre de 1716. Gentiles hombres: Francisco Piombine, Pedro Bilbao, despedido, Joseph Balberi, Juan Francisco Foronda, Roque Ceruti, maestro de capilla,

111 Autos generales de la segunda residencia que se tomó al príncipe de Santo Buono, por haberse declarado nula la que se dio en el año 1719. Pieza Primera. Lima, año de 1722. AGI, Escribanía, 553A.

112 Sobre la implicación de Lacunza en la expedición de Martinet, con la polémica sobre las cargas apresadas, se conoce un memorial del intendente veedor donde se queja de las «legítimas» partidas que el Consejo de Indias ordenó excluirle, s.f., AGI, Lima, 438.

113 Autos generales de la segunda residencia. Segunda Pieza. 30 de julio de 1724, AGI, Escribanía, 553A.

114 La Instrucción mandaba revisar una serie de papeles entre los cuales se encontraban las cartas de Cugurra. 
Federico Botomi, médico, Juan Masano, cirujano, Juan de Prados, oficial de mayordomía. Pajes: Juan Miguel de Otaisa, despedido, Francisco Castellanos, Joseph Ubalt, despedido, Elías de Salcedo, Antonio Candioti, Manuel Vitoriano, Joseph Prieto, despedido, Juan Pagano, Francisco Candete, ayuda de cámara de los señoritos, Domingo de Lara, repostero. ${ }^{115}$

Por último, cabe decir que tres fueron los cargos hechos a Santo Buono. El primero estaba relacionado con una cantidad de 400.000 pesos que tenía aprestados para mandar en septiembre de 1719, según informó por carta, pero que no envió y usó para distintas pagas del real servicio. El segundo, por el caso de los corregimientos servidos por terceros, como el caso de Cajamarca. El tercero era del mismo tenor por el caso del corregimiento de Cochabamba. ${ }^{116}$ Débil consideramos lo imputado si comparamos este resultado con los cargos formulados en la primera comisión. Como demuestra la residencia tomada a Santo Buono, el asunto de sus deudos y criados estuvo desde primera hora en el punto de mira de las comisiones que actuaron, pero los descargos presentados por Pérez de Guzmán sirvieron para una excepcional defensa del virrey. También los alegatos de la defensa sirvieron para sacar de apuros a algunos servidores, como fue el que trataba el asunto del abasto de carne y manteca en Lima, donde el abogado Pérez de Guzmán presentó varios testigos de descargo que negaban la acusación del control y monopolio de estos productos por parte de Virginio María Gritta. ${ }^{17}$ Frente a ello, siempre vigilantes estuvieron los más acérrimos enemigos del príncipe, incluso tras su marcha del Perú.

\section{Conclusiones}

Si comparamos los cargos de la primera y la segunda residencia con otras acusaciones que se habían formulado en años anteriores a otros virreyes, y las continuas críticas acerca del nepotismo ejercido por aquellos gobernantes, podemos inferir que tanto los cargos imputados como las defensas exhibidas formaban parte de un ritual que se reproducía de forma automática al término de cada gobierno. El sistema no solo permitía hacer

115 Autos generales de la segunda residencia. Segunda Pieza. 30 de julio de 1724, AGI, Escribanía, 553A, f. 7.

116 Autos generales de la segunda residencia. Segunda Pieza. 30 de julio de 1724, AGI, Escribanía, 553A, f. 136-138.

117 «Pedro Pérez de Guzman...», en John D. Rockefeller, Jr. Library, Brown University, microfilm, FHA 237.9.c.2., f. 14-17. 
públicas las quejas y acusaciones a quienes se hubieran sentido apartados en la distribución de oficios, rentas y otras mercedes, ${ }^{118}$ sino que también posibilitaba cristalizar un sistema de coacción institucionalizada cuando era necesario. En el caso de Carracciolo, la criba consistía en reprimir a los sectores santobuonistas que quedaron en Lima tras la marcha del virrey. ${ }^{119}$ Ocupaban un interés singular los familiares, criados y allegados, tanto por los beneficios adquiridos como por considerarse los fieles sucesores del príncipe italiano que seguían influyendo en la corte virreinal con sus gustos y costumbres extranjeras. ${ }^{120}$

Ello explica en parte que los ministros principales del virrey fueran sometidos a pesquisas de gran rigor. A José Potau se le investigó sobre varios excesos como juez comisionado en diversas causas relativas a la lucha contra el contrabando y, sobre todo, por su actuación en la residencia tomada a Diego Ladrón de Guevara, obispo de Quito y virrey del Perú anterior a Caracciolo. ${ }^{121}$ La residencia tomada a Luis Ambrosio Alarcón por su gestión en la mina de Huancavelica le supuso hasta pena de cárcel por un tiempo. ${ }^{122}$

118 En el caso del Castelldosrius, las denuncias partían de la propia corte virreinal, enunciadas por criollos pertenecientes a la administración de justicia en Lima. Burgos Lejonagoitia, 2010, 320.

119 Sobre los últimos días de Santo Buono en el Perú, se sabe que, tras haber solicitado el príncipe en varias ocasiones su retiro y permiso para regresar a España, tuvo lugar la ceremonia de entrega del mando a su sucesor, el arzobispo Diego Morcillo, con fecha de 26 de enero de 1720. Un año después, puso rumbo a Acapulco a bordo del navío La Peregrina conducido por el general Pedro Medranda y Vivanco, Mendiburu, 1931, III, 298. Mendiburu no señala la fecha de salida del Perú, solo indica que llegó a Cádiz en 1721. Su partida debió realizarse después de la firma del codicilo que se otorgó en Lima el 17 de enero de 1721. Codicilio testamentario y poder general, AGNL, Sección Notarial, Pedro de Espino Alvarado, Protocolo 261, f. 86-93 en Rizo-Patrón Boylan, 2001, 4. Desde México, embarcó en Veracruz en la flota del teniente general Fernando Chacón que lo conduciría a España. Parece que la precipitada llegada de Diego Morcillo a Lima para hacerse cargo del solio virreinal le costó a Santo Buono parte de su último sueldo. Se le adeudaba desde entonces un monto de 2.800 pesos, que reclamaba el príncipe en 1725, y que no se saldaría hasta la llegada del nuevo virrey marqués de Castelfuerte, AGI, Lima, 438. Citado en Moreno Cebrián, 2003, 264. Un nuevo contratiempo sufriría posteriormente Santo Buono al no promocionar a la presidencia del Consejo de Indias como pretendía, pues dicho cargo lo obtuvo su contrincante Andrés del Pez. En unas notas biográficas consta que se casó nuevamente en Madrid en 1723 con doña Isabel María Martínez —https://historiaperuana.pe/biografia/ carmine-nicola-caracciolo/ [Consultado: 23/09/2018]—. Por último, según Vargas Ugarte, regresó a Nápoles y falleció en sus estados en el año 1727.

120 Las costumbres foráneas en cuanto a fiestas, celebraciones y manifestaciones culturales sirvieron igualmente de arma arrojadiza contra Castelldosrius por parte de sus adversarios políticos. Sala i Vila, 2004, 37.

121 «Pesquisa formada a José Potau, alcalde de casa y corte por los diferentes excesos que cometió en las comisiones que le encargó el Príncipe de Santo Bono (1719)», AGI, Escribanía, 554A y B; AGNM, Consejos, 21308, exp. 4.

122 «Residencia a Luis Ambrosio de Alarcón, Superintendente de la mina de Huancavelica, por Juan Pérez de Urquizo, juez de la residencia del Príncipe de Santo Bono y por incidencia de esta. Fenecida en 1726» [1719 y 1722], AGI, Escribanía, 554A. 
El mayordomo Torelli tampoco salió bien parado al ser acusado, durante el juicio de residencia al virrey, de su implicación en el comercio de contrabando francés. Según el abogado defensor de Santo Buono, el mayordomo fue despedido, puesto preso en la cárcel de corte, con pena de destierro de esos reinos. Este hecho sirvió como prueba de descargo a favor del príncipe sobre la tolerancia del comercio con los franceses, pero las secuelas de la investigación las sufrió directamente el mayordomo genovés. Igualmente, se tienen noticias del mayordomo Candiotti, quien sufrió la represión del Santo Oficio en 1726 por sospechas de heterodoxia. ${ }^{123}$

Las críticas hacia el príncipe italiano emanaron principalmente de sectores poderosos y contrarios al sector santobuonista, unas críticas que no finalizaron tras la renuncia del príncipe al solio virreinal, sino que, por el contrario, prosiguieron e incluso arreciaron con la llegada del nuevo virrey Diego Morcillo. La enemistad manifiesta entre ambos personajes quedó plasmada en una sátira política de carácter teatral titulada No puede ser, ${ }^{124}$ donde se incluía, igualmente, una aguda crítica a las costumbres extranjeras de la corte y del propio Santo Buono y a los favoritismos hacia sus parientes. ${ }^{125} \mathrm{El}$ anónimo se hizo eco del tenso reemplazo del virrey por Morcillo, y de los obstáculos por parte del príncipe para que no actuase su enemigo declarado, el oidor Nuñez de Sanabria, como juez de su residencia. ${ }^{126}$ El enfrentamiento entre el virrey y el arzobispo que lo reemplazaba no solo respondía a antipatías personales, sino a la involucración de otros actores pertenecientes a grupos de presión y fuerza en la sociedad colonial, que llegaron a conformar bandos opuestos en coyunturas específicas como las que atienden a ese trasvase de poderes entre las dos más altas dignidades del momento en el Perú. Una cuestión que ya puso en el centro del debate Pierre Ragón para su estudio sobre la corrupción en la Nueva España. ${ }^{127}$

La Relación de 1722, mencionada y atribuida al abad Barberí, era asimismo testigo del virreinato que había dejado Santo Buono, cuya corte es-

123 Patrucco, 2011, 967.

124 La obra completa se encuentra en la Sección de Manuscritos Importantes de la Biblioteca Nacional de Lima, tomo 165, f. 47-82, indicado en Patrucco, 2005, 119. Según Lohman, la obra no se llegó a representar en ningún escenario, pero cumplió la función que tenía este tipo de géneros literarios, a modo de panfletos, de hacerla circular para su lectura. Lohmann Villena, 1945, 371-373.

125 Patrucco, 2017, 232-233.

126 Señala Patrucco, basándose en la obra anónima, que Santo Buono intentó privarle de voz, voto y presidencia de la Audiencia, «recusándole de haberse pretendido encumbrar como gobernador interino y de haber convocado al Acuerdo sin licencia del Virrey para abrir los pliegos». Patrucco, $2005,120$.

127 Ragón, 2018, 17-29. 
taría en los años siguientes marcada por las intrigas ${ }^{128}$. Fueron célebres los enfrentamientos entre Morcillo y el sector santobuonista. Moreno Cebrián presenta un cuadro de enredos protagonizado por la persecución de Morcillo a los «maquiavélicos» santobuonistas que quedaron en Lima, a quienes acusaba de complot contra su persona. Uno de ellos era Barberí, que sería acusado por Morcillo de sujeto contrario al regio patronato, ordenando su prisión. ${ }^{129}$ Otro de los incondicionales que quedó allí fue Luis Ambrosio Alarcón. Su fidelidad a Santo Buono le acarreó no pocos problemas y la enemistad de algunos de los enemigos públicos del príncipe, entre ellos, los oidores Miguel Núñez y Juan de Echevarría. En consecuencia, soportó la persecución e investigación por su gestión al frente de la superintendencia de la mina de Huancavelica ordenada por Morcillo. Tras la pesquisa, fue declarado culpable, sufriendo prisión en la cárcel de Lima, aunque posteriormente, revisado el juicio, sería absuelto. ${ }^{130}$

Para finalizar, queremos indicar que el juicio de residencia a Santo Buono respondía, como tantas otras residencias tomadas en las colonias de Ultramar, a un dispositivo de control establecido para garantizar el buen gobierno del príncipe. Pero la corte que instaló el nuevo virrey, integrada por numerosos deudos y criados — muchos de origen italiano-, influyó de manera notable para sembrar la desconfianza sobre la fórmula ideal de buen gobierno. La introducción de gustos y costumbres foráneos y el posible enriquecimiento del virrey y sus familiares sirvieron como arma arrojadiza para los detractores del virrey. Cuestión puesta de manifiesto sobre todo en el primer juicio de residencia.

Así pues, la corrupción, el fraude o el nepotismo pudieron dar un rumbo determinado al inicio de este trabajo, pero a medida que se ha indagado y profundizado sobre el tema de la corrupción, se hace más evidente que aquellos vicios, alteraciones, abusos o acciones constitutivas de delitos, tanto de virreyes como de otros elevados cargos de la administración indiana, formaban parte de un dispositivo que, en palabras de Andújar, «engrasaba el sistema», ${ }^{131}$ un sistema en el que todos eran partes coadyuvantes y generadoras de esas prácticas, bien fuera de la ley, bien al límite de esta. El ejemplo más claro de este juego artificioso lo hallamos en aquel pacto

128 Tal cuadro de intrigas era la nota dominante en la vida virreinal del Perú desde los inicios del siglo XVIII, Sáenz-Rico, 1978, 123.

129 Para los sucesos posteriores sobre el encarcelamiento, juicio, orden de deportación y llegada a Roma como prófugo, véase Moreno Cebrián, 2003, 257-262.

130 Ibidem, 270.

131 Andújar, 2008, 12. 
suscrito entre el príncipe y el rey en enero de 1713, que expusimos líneas arriba. Por último, hay que expresar ciertas dudas sobre el grado de eficacia que ofreció la residencia practicada a Santo Buono, ${ }^{132}$ pues, sin duda, esta estuvo desde sus inicios muy vinculada a determinados intereses políticos. Ello explica los altercados entre los propios comisionados que actuaron en la primera residencia, donde una vez más se manifestaron los aliados del virrey y sus rivales, todos excesivamente vinculados con la acción política. Así pues, la norma jurídica dictada sobre el juicio de residencia del príncipe servía, más que otra cosa, de cortina de humo, tras la cual se encontraban los intereses personales, políticos, culturales o morales de todos los actores que intervinieron en el proceso, incluido también los de algún criado rencoroso y vengativo.

Recibido, 9 de enero de 2019 Segunda versión, 11 de abril de 2019 Aceptado, 29 de abril de 2019

\section{Referencias bibliográficas}

Andújar Castillo, Francisco, Necesidad y venalidad: España e Indias, 1704-1711, Madrid, Centro de Estudios Políticos y Constitucionales, 2008.

Andújar Castillo, Francisco y Ponce Leiva, Pilar (coords.), Debates sobre la corrupción en el mundo ibérico, siglos XVI-XVIII, Alicante, Biblioteca Virtual de Cervantes, 2018.

Balzo, Bertrando del, «Familias nobles y destacadas del Perú en los informes secretos de un virrey napolitano», Revista del Instituto Peruano de Investigaciones Genealógicas, 14, Lima, 1965, 107-133.

Bermúdez de la Torre y Solier, Pedro J., El Sol en el Zodiaco. Certamen poético en el solemne, triunfal recibimiento del Excelentísimo Señor Don Carmine Nicolás Caracciolo Príncipe de Santo Buono, y Grande de España, duque del Castel di Sangro, marqués de Buquianco, conde de Esquiavi, Santovito y Capracota, señor de la ciudad de Añón, barón de Grandinamarca, Castelnuovo, Castellón, Belmonte, Roca, Espinalbeti, Frame, Friffa, Guandinaria, Guardiagreli, Ripa, Teatina, Roca del Raffo, y Monte Ferrante. Del Consejo de Su Magestad, Virrey, Gobernador y Capitán General destos Reinos del Perú, Tierra Firme y Chile, etc. En la Real Universidad de San Marcos de

132 Ponce cuestiona el grado de eficacia de los juicios de residencia como instrumentos del control al ser utilizada tal herramienta de carácter jurídica como un arma contra el rival político. Ponce, $2018,347$. 
esta ciudad de Lima, Corte del Perú. Escribíale D. Pedro Joseph Bermúdez de la Torre y Solier, Alguacil Mayor de la Real Audiencia, de la mesma ciudad de Lima. Con Licencia, Lima, Francisco Sobrino, 1717.

Burgos Lejonagoitia, Guillermo, «Los documentos "secretos” de las negociaciones del Marqués del Castelldosrius, virrey del Perú», Chronica Nova, 36, Granada, 2010, 317-338.

Burkholder, Mark A. y Chandler, D. S., Biographical Dictionary of Audiencia Ministers in the Americas, 1687-1821, Westport, Greenwood Press, 1982.

Burkholder, Mark A., Biographical Dictionary of Councilors of the Indies, 17171808, Westport, Greenwood Press, 1986.

Cañeque, Alejandro, «Los virreinatos de América en los siglos XVI y XVII: un gobierno de parientes y amigos», en Suárez, Margarita (ed.), Parientes, criados y allegados: los vínculos personales en el mundo virreinal peruano, Lima, Pontificia Universidad Católica del Perú/Instituto Riva-Agüero, 2017, 21-36.

Costa Vigo, L. Miguel, «Por no yr tan solo. Redes clientelares y dinámicas de poder en el virreinato del Perú: el caso del gobierno del virrey conde del Villar, 1585-1590», en Suárez, Margarita (ed.), Parientes, criados y allegados: los vínculos personales en el mundo virreinal peruano, Lima, Pontificia Universidad Católica del Perú/Instituto Riva-Agüero, 2017, 37-67.

Cuart Moner, Baltasar, «De Bolonia a las Indias: los colegiales de San Clemente en la administración americana durante el siglo XVIII», Estudios de Historia social y económica de América, 16-17, Alcalá de Henares, 1998, 170-189.

Fernández Duro, Cesáreo, Armada Española desde la unión de los reinos de Castilla y de León, Madrid, Sucesores de Rivadeneyra, 1895-1903, 9 vols.

Gómez, Santiago, «La escuadra corsaria de Martinet en el Pacífico, 1717-1719», Todoababor.es, España, 8 de febrero de 2006. Disponible en: www.todoaba bor.es/articulos/martinet.htm [Consultado: 04/01/2019].

Latasa, Pilar, «Poder y favor en la corte virreinal: los criados del marqués de Montesclaros (1607-1615)», Histórica, XXXVI, 2, Perú, 2012, 49-84.

Lohmann Villena, Guillermo, El arte dramático en Lima durante el virreinato, Madrid, Consejo Superior de Investigaciones Científicas/Escuela de Estudios Hispano-Americanos, 1945.

Mendiburu, Manuel de; Riva-Agüero, José de la y San Cristóbal, Evaristo, Diccionario histórico-biográfico del Perú [Segunda edición], Lima, Imprenta Enrique Palacios, 1931, 12 vols.

Moreno Cebrián, Alfredo, «El regalismo borbónico frente al poder vaticano: acerca del estado de la Iglesia en el Perú durante el primer tercio del siglo XVIII», Revista de Indias, LXIII, 227, Madrid, 2003, 223-274.

Moreno Cebrián, Alfredo y Sala i Vila, Núria, El premio de ser virrey: los intereses públicos y privados del gobierno virreinal en el Perú de Felipe V, Madrid, Consejo Superior de Investigaciones Científicas, 2004. 
Patrucco Núñez, Sandro, Italianos en la Lima borbónica (1700-1800). Su presencia e inserción en la sociedad virreinal, tesis de magister en Historia, Pontificia Universidad Católica del Perú, Escuela de Graduados, Lima, 2005.

Patrucco Núñez-Carvallo, Sandro, «Inserción italiana en el Perú virreinal del siglo XVIII», en Herrero Sánchez, Manuel et al., (coords.), Génova y la Monarquía Hispánica (1528-1713), Génova, Atti della Società Ligure di Storia Patria, vol. I, 2011.

Patrucco Núñez-Carvallo, Sandro, «Un virrey napolitano y su numerosa familia en el Perú: el príncipe de Santo Buono (1716-1720)», en Ciaramitaro, Fernando y De la Puente Brunke, José (coords.), Extranjeros, naturales y fronteras en la América ibérica y Europa (1492-1830), México, Universidad Autónoma de la Ciudad de México/ EDITUM-Ediciones de la Universidad de Murcia/ Red Columnaria, 2017.

Porro Girardi, Nelly R., «Los criados en Indias: presencia y significado (siglo XVI)», Memoria de X Congreso del Instituto Internacional de Historia del Derecho Indiano, México, Universidad Nacional Autónoma de México, 1995, 1221-1253.

Rizo-Patrón Boylan, Paul, Linaje, dote y poder: la nobleza de Lima de 1700 a 1850, Lima, Pontificia Universidad Católica del Perú/Fondo Editorial, 2001.

Rosenmüller, Christoph, Patrons, partisans, and palace intrigues. The court society of colonial Mexico, 1702-1710, Calgary, University of Calgary Press, 2008.

Sáenz-Rico Urbina, Alfredo, «Las acusaciones contra el virrey del Perú, Marqués de Castelldosrius, y sus "noticias reservadas" (febrero 1709)», Boletín Americanista, 28, Barcelona, 1978, 119-135.

Sala i Vila, Núria, «La escenificación del poder: el marqués de Castelldosrius, primer virrey Borbón del Perú (1707-1710)», Anuario de Estudios Americanos, 61, 1, Sevilla, 2004, 31-68.

Salazar, Lorenzo, Relazione e giornale del viaggio dell'ecc.mo sig.e Pnpe di Santo Buono vice re del Perù con li vascelli che partirono dalla Bahia di Cadice li 14 9mbre 1715 sino a Cartagena dell'Indie Occidentali: manoscritto della Biblioteca di San Martino, dato in Luce ed annotato da Lorenzo Salazar, Nápoles, Angelis \& Bellisario, 1894.

Suárez, Margarita, «Beneméritos, criados y allegados durante el gobierno del virrey conde de Castellar: ¿el fin de la administración de los parientes?», en Suárez, Margarita (ed.), Parientes, criados y allegados: los vínculos personales en el mundo virreinal peruano, Lima, Pontificia Universidad Católica del Perú/ Instituto Riva-Agüero, 2017, 69-95.

Sullón Barreto, Gleydi, «Los criados portugueses del príncipe de Esquilache, virrey del Perú, 1615-1621», Memoria y Civilización, 21, Pamplona, 2018, 213-244.

Torres Arancivia, Eduardo, Corte de virreyes. El entorno del poder en el Perú en el siglo XVII, Lima, Pontificia Universidad Católica del Perú, 2006. 
Vargas Ugarte, Rubén, Historia General del Perú [Tercera edición], Lima, Carlos Milla Batres, 1981, 6 vols.

Villarreal Brasca, Amorina, «El privado del virrey: vínculos, prácticas y percepciones del favor en la gestión del príncipe de Esquilache», Memoria y Civilización, 21, Pamplona, 2018, 141-165. 